\title{
The influence of adiponectin G276T gene polymorphism on changes in total and high molecular weight adiponectin levels by exercise training
}

\author{
Daisuke Ando ${ }^{1,4^{*}}$, Yoshiyuki Hosaka ${ }^{2}$, Kohta Suzuki $^{3}$, Zentaro Yamagata ${ }^{4}$ \\ ${ }^{1}$ Department of Physical Education, National Defense Academy, Kanagawa, Japan; *Corresponding Author: ando@nda.ac.jp \\ ${ }^{2}$ Hosaka DM Clinic, Yamanashi, Japan; \\ ${ }^{3}$ Center for Birth Cohort Studies, Interdisciplinary Graduate School of Medicine and Engineering, University of Yamanashi, Yama- \\ nashi, Japan; \\ ${ }^{4}$ Department of Health Sciences, Interdisciplinary Graduate School of Medicine and Engineering, University of Yamanashi, Yama- \\ nashi, Japan.
}

Received 18 October 2011; revised 15 November 2011; accepted 24 November 2011.

\begin{abstract}
Adiponectin is an adipocyte-secreted hormone and regulates the metabolism of lipid and glucose. We examined the influence of adiponectin G276T gene polymorphism on changes in total or high molecular weight adiponectin levels by exercise training. A randomized parallel-design study ( $n=53 ; 40$ women and 13 men; age range, 32 - 65 years) was conducted. Participants were randomly assigned to the exercise $(n=26)$ or control $(n=27)$ group and received exercise training for 70 min 2 times per week for 12 weeks and exercise advice at the baseline, respectively. Blood sample were obtained before and after the intervention. The primary outcomes were changes in total adiponectin and high molecular weight adiponectin levels. At the baseline, the participants with and without $276 \mathrm{G}$ allele did not differ with the total and high molecular weight adiponectin levels in the entire study population. No significant difference in the change in the total and high molecular weight adiponectin levels between the subjects with the G276G genotype and 276T allele carriers were found. This study provides evidence that the G276T polymorphism of the adiponectin gene is not associated with the magnitude of the effect of twice-weekly exercise training on the total and high molecular weight adiponectin levels.
\end{abstract}

Keywords: Exercise; High Molecular Weight Adiponectin; Adipocytokine; Genotype

\section{INTRODUCTION}

Adiponectin is the most abundantly secreted adipokine [1]. It has been reported to play a role in the development of insulin resistance [2], obesity [3], hyperlipidemia [4], type 2 diabetes mellitus [5], and cardiovascular diseases [6].

Exercise training improves many components of the metabolic risk factor profile [7]; therefore, it can be speculated that adiponectin is involved in the regulation of glucose or lipid metabolism through exercise training. Previous studies have revealed that the effects of exercise training modify according to the genetic background [8-10]. It has been shown that the adiponectin gene contains a polymorphism at position $276(\mathrm{G} / \mathrm{T})$. The polymorphism is located in intron 2 of the adiponectin gene [11]. The adiponectin G276T gene polymorphism has been shown to be associated with type 2 diabetes, insulin resistance, and serum adiponectin levels [11,12]. Furthermore, Huang et al. showed that the G276T polymorphism of the adiponectin gene affects of the magnitude of the effects of exercise training on the circulating total adiponectin levels [13]. However, the influence of adiponectin gene polymorphism on the change in circulating adiponectin level by exercise training has not been well documented.

Additionally, adiponectin circulates in blood in multimeric isoforms. Previous studies on multimer formation in blood have demonstrated that high molecular weight (HMW) adiponectin is the active form of proteins $[14,15]$. To date, the effects of gene polymorphism on exercise-training-induced changes in the HMW adiponectin levels is still unclear. Thus, we examined the effects of adiponectin G276T gene polymorphism on the changes in total or HMW adiponectin levels by twice- 
weekly exercise training.

\section{METHODS}

\subsection{Study Population}

We randomly assigned 53 Japanese people (36 women and 17 men) to exercise and control groups using a parallel-design study, which was performed at the fitness club. Based on the checkup data, we included women and men aged from 30 to 70 years with a glycosylated hemoglobin level of $5.5 \%-6.4 \%$ or plasma glucose level of $110-125 \mathrm{mg} / \mathrm{dl}$. The study was approved by the Ethical Review Committee, Faculty of Medicine, University of Yamanashi. All the participants provided written informed consent.

\subsection{Intervention}

Exercise group: The subjects exercised at the fitness club two times per week for 12 weeks. Each exercise session lasted $<70$ min and included a 5-min warm up, 40-min resistance exercise, 20-min aerobic exercise, and 5 -min cool down. A minimum of two days elapsed between two consecutive training sessions. 1) Resistance exercise: the resistance exercise program consisted of four exercises using resistance exercise machines (chest press, pull downs, knee extension, and knee flexion) for 3 sets of 7 - 15 repetitions and 4 exercises using free weights (leg lunges, heel raises, sit ups, and back extensions) for 3 sets of 10 - 20 repetitions. The training intensities using resistance exercise machines were $60 \%$ $80 \%$ of the baseline one repetition maximum (1-RM). Initial training loads were $60 \%$ of baseline 1-RM and were increased to $80 \%$ of baseline 1-RM by the end of the study. 2) Aerobic exercise: the subjects exercised on a bicycle ergometer for 20 min per session. The training intensity was adjusted to maintain a constant heart rate between $60 \%$ and $75 \%$ heart rate reserve, which was calculated using the following formula: (maximum heart rate - resting heart rate) $\times 0.6-0.75+$ resting heart rate. The maximal heart rate for each subject was calculated as 220 minus the age of the subject. The dietary intake was not restricted throughout the trial period in both the groups.

Control group: Participants in the control group were given individual advice on the way to undertake homebased resistance exercise to be performed for about 30 min at the baseline.

\subsection{Outcome Measures}

We assessed the outcome measures at the baseline and those at 12 weeks. Biochemical measurements were collected in the fasting state. Twelve-week blood collection was performed $48-72 \mathrm{~h}$ after the last exercise session to eliminate the effect of the last acute bout of exercise on all the blood parameters. The outcome measures were carried out in a blinded fashion.

Serum samples for total adiponectin and HMW adiponectin levels were stored at $-80^{\circ} \mathrm{C}$ until assayed. The total serum adiponectin concentrations were measured by sandwich ELISA, (Otsuka Pharmaceuticals, Tokyo, Japan), as described previously [3]. Serum HMW adiponectin was measured by means of a novel sandwich ELISA using a monoclonal antibody to human HMW adiponectin, as described previously [16]. This sandwich ELISA, essentially measuring only HMW adiponectin in the serum, is now available as a kit from Fujirebio (Tokyo, Japan).

\subsection{Genotyping}

Genomic DNA was extracted from the entire blood with a FlexiGene DNA Kit (QIAGEN, Hilden, Germany) according to the manufacturer's protocol. Genotyping of the G276T polymorphism of adiponectin gene was performed with the polymerase chain reaction-restriction fragment length polymorphism [17]. The sequences of the primers were 5'-GGC CTC TTT CAT CAC AGA CC-3' (forward primer) and 5'-AGA TGC AGC AAA GCC AAA GT-3' (reverse primer). The PCR amplifications were carried out in 20- $\mu \mathrm{l}$ reaction volumes containing $0.2 \mathrm{mM}$ of dNTP, $1.5 \mathrm{mM}$ of magnesium chloride, $0.5 \mathrm{U}$ of Taq polymerase (Takara, Tokyo, Japan), 50 ng of genomic DNA, and $0.2 \mu \mathrm{M}$ of each of the primers. After the initial denaturation at $95^{\circ} \mathrm{C}$ for $5 \mathrm{~min}, 35$ cycles of PCR were done for $60 \mathrm{~s}$ at $95^{\circ} \mathrm{C}$, for $45 \mathrm{~s}$ at $58^{\circ} \mathrm{C}$, and for $45 \mathrm{~s}$ at $72^{\circ} \mathrm{C}$, with a final extension at $72^{\circ} \mathrm{C}$ for $5 \mathrm{~min}$. The PCR product of $196 \mathrm{bp}$ fragment was digested with 10 units of PctI (Sib Enzyme Ltd., Novosibirsk, Russia) in a reaction mixture of $10 \mu \mathrm{l}$ for $8 \mathrm{~h}$ at $37^{\circ} \mathrm{C}$. The digested PCR products were applied to the electrophoresis of $2 \%$ agarose gel and visualized by ethidium bromide.

\subsection{Statistical Analysis}

All the analyses followed an intention-to-treat principle using all randomized participants and assuming no change from the baseline for those with missing data. To compare the continuous variables between the groups in baseline, the one-way ANOVA was used. The data after intervention was analyzed by two-way ANOVA (intervention $\times$ genotype). The significance level was established at $P<0.05$. The results are expressed as mean \pm standard deviation (SD) or mean \pm mean standard error (SE). All the analyses were performed using SPSS 17.0 for Windows. 


\section{RESULTS}

\subsection{Participants}

Of the 53 women and men enrolled, 49 underwent follow-up evaluations. One participant in the control group (one woman) refused final testing for personal reasons; three participants in the exercise group (one man and two women) dropped out citing personal or medical reasons unrelated to the study. We included 53 participants in the intention-to-treat analysis.

\subsection{Effects of Adiponectin Gene Polymorphism}

DNA was available from all the subjects. The G276G genotype was found in 24 subjects (45.3\%), the G276T genotype was found in 21 subjects (39.6\%), and the T276T genotype was found in 8 subjects (15.0\%). In the exercise group, the G276G genotype was found in 11 subjects (42.3\%) and 276T allele was found in 15 subjects (57.7\%). In the control group, the G276G genotype was found in 13 subjects (48.2\%) and 276T allele was found in 14 subjects (52.8\%). Because the frequency of the T276T genotype was low, we combined it with the G276T genotype in all the statistical analyses [13].

At the baseline, the participants with and without 276G allele did not differ with the total and HMW adiponectin levels in the entire study population (data not shown) or within the exercise group and the control group (Table 1). No significant difference in the change in the total and HMW adiponectin levels between the subjects with the G276G genotype and 276T allele car- riers of the adiponectin gene were found (Table 2).

\section{DISCUSSION}

The most important finding in this study is that the change in the total and HMW adiponectin levels by twice-weekly exercise training was not associated with adiponectin G276T gene polymorphism.

The beneficial effect of exercise varies for each individual and may be affected not only by the environmental conditions but also the genetic background [8] To date, few reports have investigated the effect of gene polymorphism on exercise-training-induced changes in the total adiponectin levels $[13,18]$. In this study, the change in the total adiponectin by exercise training was not modified by the G276T polymorphism of the adiponectin gene. However, in contrast to our results, Huang et al. showed that the G276T polymorphism of the adiponectin gene was associated with the magnitude of the effects of exercise training on the circulating total adiponectin levels [13]. The difference of the study design is suggested as one reason for the discrepancy. The data of before-after trial is used in the study by Huang et al. though the data of randomized controlled trial is used in our study. Moreover, the exercise regimen in the study by Huang et al. was 5 days/week for 6 months. In contrast, the exercise regimen in our study was 2 days/week for 12 weeks. Differences in the duration or/and fre-quency of exercise training could explain these different results. It would be useful to further investigate whether the adiponectin allelic variants affect changes in the circulating total adiponectin levels by the various exercises

Table 1. Subject characteristics at baseline.

\begin{tabular}{|c|c|c|c|c|c|}
\hline \multirow{2}{*}{ Characteristic } & \multicolumn{2}{|c|}{ Exercise } & \multicolumn{2}{|c|}{ Control } & \multirow{2}{*}{$P$ value ${ }^{*}$} \\
\hline & G276G genotype $(\mathrm{n}=11)$ & 276T genotype $(n=15)$ & G276G genotype $(\mathrm{n}=13)$ & 276T genotype $(n=14)$ & \\
\hline Age (yr) & $58.6 \pm 6.2$ & $53.9 \pm 8.3$ & $54.9 \pm 7.7$ & $57.4 \pm 9.6$ & 0.44 \\
\hline Weight (kg) & $56.6 \pm 13.0$ & $61.6 \pm 11.3$ & $61.1 \pm 11.4$ & $53.1 \pm 10.2$ & 0.18 \\
\hline BMI & $22.8 \pm 3.1$ & $24.7 \pm 3.8$ & $23.6 \pm 3.4$ & $22.0 \pm 3.7$ & 0.21 \\
\hline Total adiponectin $(\mu \mathrm{g} / \mathrm{ml})$ & $10.4 \pm 4.0$ & $9.7 \pm 3.8$ & $9.5 \pm 6.2$ & $12.1 \pm 6.3$ & 0.53 \\
\hline HMW adiponectin $(\mu \mathrm{g} / \mathrm{ml})$ & $6.8 \pm 4.2$ & $6.5 \pm 3.7$ & $5.5 \pm 4.3$ & $7.4 \pm 4.7$ & 0.70 \\
\hline
\end{tabular}

Note: Values are expressed as means \pm SD. Abbreviations: BMI, body mass index; HMW, high-molecular-weight. *One-way ANOVA.

Table 2. Weight, BMI, total adiponectin, HMW adiponectin levels: change with intervention by adiponectin polymorphism.

\begin{tabular}{|c|c|c|c|c|c|}
\hline & \multicolumn{2}{|c|}{ Exercise } & \multicolumn{2}{|c|}{ Control } & \multirow[b]{2}{*}{ Intervention $\times$ genotype } \\
\hline & $\begin{array}{l}\text { G276G genotype } \\
(\mathrm{n}=11)\end{array}$ & $\begin{array}{l}276 T \text { genotype } \\
\qquad(\mathrm{n}=15)\end{array}$ & $\begin{array}{l}\text { G276G genotype } \\
\qquad(\mathrm{n}=11)\end{array}$ & $\begin{array}{l}276 \mathrm{~T} \text { genotype } \\
\quad(\mathrm{n}=15)\end{array}$ & \\
\hline BMI & $-0.02 \pm 0.13$ & $-0.40 \pm 0.37$ & $-0.26 \pm 0.18$ & $-0.03 \pm 0.11$ & 0.22 \\
\hline Total adiponectin $(\mu \mathrm{g} / \mathrm{ml})$ & $-0.47 \pm 0.94$ & $0.19 \pm 0.58$ & $-0.02 \pm 0.60$ & $-0.49 \pm 0.57$ & 0.40 \\
\hline HMW adiponectin $(\mu \mathrm{g} / \mathrm{ml})$ & $-0.30 \pm 0.79$ & $-0.59 \pm 0.37$ & $0.05 \pm 0.36$ & $-0.17 \pm 0.28$ & 0.85 \\
\hline
\end{tabular}

Note: Values are expressed as means \pm SE. Abbreviations: BMI, body mass index; HMW, high-molecular-weight. "Two-way ANOVA; P value for Interaction in model. 
training regimen. Additionally, it will be necessary to examine subject difference in the further studies. Shin et al. reported that G276T polymorphism of the adiponectin gene associates with different responses of total adiponectin to mild weight loss in overweight-obese subject [19]. More recently, Chung et al. indicated that adiponectin genetic variants affects total adiponectin levels in with impaired fasting glucose or newly diagnosed type 2 diabetes in response to dietary intervention [20]. However, our study subjects included non-obese individuals. There is a possibility that a different result is obtained when the same exercise program to the present study is executed to the individuals with obesity, impaired fasting glucose or type 2 diabetes.

It has been shown that HMW adiponectin strongly correlates with glucose tolerance as compared to the total adiponectin [21], and HMW adiponectin has proven to be more successful than other multimers at reducing blood glucose levels [22]. In the present study, the change in the HMW adiponectin by exercise training was not modified by the G276T polymorphism of the adiponectin gene. To our knowledge, this is the first study to show the HMW adiponectin levels changes with exercise training may not be influenced by the G276T polymorphism of the adiponectin gene. The experimental study evaluating the effect of adiponectin allelic variants on the change in the HMW adiponectin levels in various exercise protocol are needed to more completely understand the influence of adiponectin allelic variants on the changes in adiponectin oligomer distribution by exercise training.

This study has some important limitations. The exercise type in our study was combination of resistance and aerobic exercise. These two types of exercise produce different effects and may alter glucose metabolism through different mechanisms [23]. Further studies are needed to clarify the effect of exercise type. Second, several single nucleotide polymorphisms have been identified in the adiponectin gene [24]. We did not genotype other adiponectin gene polymorphisms. Therefore, we could not exclude the possibility that interaction of other polymorphism of the adiponectin gene with the G276T polymorphism of the adiponectin gene. Furthermore, it has been shown that the fat mass-and obesityassociated (FTO) gene polymorphism may affect circulating adiponectin levels through the changes in BMI [25]. Therefore, the genetic variants of other genes may affect changes in circulating adiponectin levels by exercise training. Finally, our observations and conclusions are limited by small sample size. Most studies assessing the effect of genes polymorphism on particular disease have larger sample size. Thus, our present findings should be verified in an independent sample.
In conclusion, the present study provides evidence that the G276T polymorphism of the adiponectin gene is not associated with the magnitude of the effect of twiceweekly exercise training on the total and HMW adiponectin levels.

\section{ACKNOWLEDGEMENTS}

This study was supported by a Grant-in-Aid (\#17390182 to Zentaro Yamagata; \#19700541 to Daisuke Ando) for scientific research from the Ministry of Education, Culture, Sports, Science and Technology, Japan. The authors thank Dr. Katsuhiro Koyama for their useful discussions and Mr. Fuminao Sekiguchi for help in extracting the Genomic DNA. Gratitude is expressed to the staff at the Fujiyosida city hall and the Nishikatsura town hall for participant recruitment.

\section{REFERENCES}

[1] Yamauchi, T., Kamon, J., Waki, H., Terauchi, Y., Kubota, N., Hara, K., Mori, Y., Ide, T., Murakami, K., Tsuboyama-Kasaoka, N., Ezaki, O., Akanuma, Y., Gavrilova, O., Vinson, C., Reitman, M.L., Kagechika, H., Shudo, K., Yoda, M., Nakano, Y., Tobe, K., Nagai, R., Kimura, S., Tomita, M., Froguel, P. and Kadowaki, T. (2001) The fatderived hormone adiponectin reverses insulin resistance associated with both lipoatrophy and obesity. Nature Medicine, 7, 941-946. doi:10.1038/90984

[2] Yamamoto, Y., Hirose, H., Saito, I., Nishikai, K. and Saruta, T. (2004) Adiponectin, an adipocyte-derived protein, predicts future insulin resistance: Two-year followup study in Japanese population. The Journal of Clinical Endocrinology \& Metabolism, 89, 87-90. doi:10.1210/jc.2003-031163

[3] Arita, Y., Kihara, S., Ouchi, N., Takahashi, M., Maeda, K., Miyagawa, J., Hotta, K., Shimomura, I., Nakamura, T., Miyaoka, K., Kuriyama, H., Nishida, M., Yamashita, S., Okubo, K., Matsubara, K., Muraguchi, M., Ohmoto, Y., Funahashi, T. and Matsuzawa, Y. (1999) Paradoxical decrease of an adipose-specific protein, adiponectin, in obesity. Biochemical and Biophysical Research Communications, 257, 79-83. doi:10.1006/bbrc.1999.0255

[4] Saltiel, A.R. and Kahn, C.R. (2001) Insulin signalling and the regulation of glucose and lipid metabolism. $\mathrm{Na}$ ture, 414, 799-806. doi:10.1038/414799a

[5] Lindsay, R.S., Funahashi, T., Hanson, R.L., Matsuzawa, Y., Tanaka, S., Tataranni, P.A., Knowler, W.C. and Krakoff, J. (2002) Adiponectin and development of type 2 diabetes in the Pima Indian population. Lancet, 360, 5758. doi:10.1016/S0140-6736(02)09335-2

[6] Schulze, M.B., Shai, I., Rimm, E.B., Li, T., Rifai, N. and $\mathrm{Hu}$, F.B. (2005) Adiponectin and future coronary heart disease events among men with type 2 diabetes. Diabetes, 54, 534-539. doi:10.2337/diabetes.54.2.534

[7] Hawley, J.A. and Houmard, J.A. (2004) Introductionpreventing insulin resistance through exercise: A cellular approach. Medicine \& Science in Sports \& Exercise, 36, 1187-1190. doi:10.1249/01.MSS.0000132382.95142.71

[8] Bray, M.S., Hagberg, J.M., Pérusse, L., Rankinen, T., Roth, S.M., Wolfarth, B. and Bouchard, C. (2009) The 
human gene map for performance and health-related fitness phenotypes: The 2006-2007 update. Medicine \& Science in Sports \& Exercise, 41, 35-73. doi:10.1249/MSS.0b013e3181844179

[9] Hand, B.D., Kostek, M.C., Ferrell, R.E., Delmonico, M.J., Douglass, L.W., Roth, S.M., Hagberg, J.M. and Hurley, B.F. (2007) Influence of promoter region variants of insulin-like growth factor pathway genes on the strength-training response of muscle phenotypes in older adults. Journal of Applied Physiology, 103, 1678-1687. doi:10.1152/japplphysiol.00420.2007

[10] Teran-Garcia, M., Rankinen, T., Rice, T., Leon, A.S., Rao, D.C., Skinner, J.S. and Bouchard, C. (2007) Variations in the four and a half LIM domains 1 gene (FHL1) are associated with fasting insulin and insulin sensitivity responses to regular exercise. Diabetologia, 50, 1858-1866. doi:10.1007/s00125-007-0733-X

[11] Hara, K., Boutin, P., Mori, Y., Tobe, K., Dina, C., Yasuda, K., Yamauchi, T., Otabe, S., Okada, T., Eto, K., Kadowaki H., Hagura, R., Akanuma, Y., Yazaki, Y., Nagai, R., Taniyama, M., Matsubara, K., Yoda, M., Nakano, Y., Tomita, M., Kimura, S., Ito, C., Froguel, P. and Kadowaki, T. (2002) Genetic variation in the gene encoding adiponectin is associated with an increased risk of type 2 diabetes in the Japanese population. Diabetes, 51, 536540. doi:10.2337/diabetes.51.2.536

[12] Qi, L., Li, T., Rimm, E., Zhang, C., Rifai, N., Hunter, D., Doria, A. and Hu, F.B. (2005) The +276 polymorphism of the APM1 gene, plasma adiponectin concentration, and cardiovascular risk in diabetic men. Diabetes, 54, 1607-1610. doi:10.2337/diabetes.54.5.1607

[13] Huang, H., Tada-Iida, K., Murakami, H., Saito, Y., Otsuki, T., Iemitsu, M., Maeda, S., Sone, H., Kuno, S. and Ajisaka, R. (2007) Influence of adiponectin gene polymerphism SNP276 (G/T) on adiponectin in response to exercise training. Endocrine Journal, 54, 879-886. doi:10.1507/endocri.K06-146

[14] Kadowaki, T. and Yamauchi, T. (2005) Adiponectin and adiponectin receptors. Endocrine Reviews, 26, 439-451. doi: 10.1210/er.2005-0005

[15] Matsuzawa, Y. (2006) The metabolic syndrome and adipocytokines. FEBS Letters, 580, 2917-2921. doi:10.1016/j.febslet.2006.04.028

[16] Nakano, Y., Tajima, S., Yoshimi, A., Akiyama, H., Tsushima, M., Tanioka, T., Negoro, T., Tomita, M. and Tobe, T. (2006) A novel enzyme-linked immunosorbent assay specific for high-molecular-weight adiponectin. The Journal of Lipid Research, 47, 1572-1582. doi:10.1194/jlr.D600010-JLR200

[17] Xita, N., Georgiou, I., Chatzikyriakidou, A., Vounatsou, M., Papassotiriou, G.P., Papassotiriou, I. and Tsatsoulis, A. (2005) Effect of adiponectin gene polymorphisms on circulating adiponectin and insulin resistance indexes in women with polycystic ovary syndrome. Clinical Chemistry, 51, 416-423. doi:10.1373/clinchem.2004.043109

[18] Mousavinasab, F., Tahtinen, T., Jokelainen, J., Koskela, P., Vanhala, M., Oikarinen, J., Keinanen-Kiukaanniemi, S. and Laakso, M. (2005) Effect of the Pro12Ala polymerphism of the PPAR2 gene on serum adiponectin changes. Endocrine, 27, 307-309. doi:10.1385/ENDO:27:3:307

[19] Shin, M.J., Jang, Y., Koh, S.J., Chae, J.S., Kim, O.Y., Lee, J.E., Ordovas, J.M. and Lee, J.H. (2006) The association of SNP276G > T at adiponectin gene with circulating adiponectin and insulin resistance in response to mild weight loss. International Journal of Obesity, 30, 1702-1708. doi:10.1038/sj.ijo.0803338

[20] Chung, H.K., Chae, J.S., Hyun, Y.J., Paik, J.K., Kim, J.Y., Jang, Y., Kwon, H.M., Song, Y.D., Lee, H.C. and Lee, J.H. (2009) Influence of adiponectin gene polymorphisms on adiponectin level and insulin resistance index in response to dietary intervention in overweight-obese patients with impaired fasting glucose or newly diagnosed type 2 diabetes. Diabetes Care, 32, 552-558. doi:10.2337/dc08-1605

[21] Fisher, F.F., Trujillo, M.E., Hanif, W., Barnett, A.H., McTernan, P.G., Scherer, P.E. and Kumar, S. (2005) Serum high molecular weight complex of adiponectin correlates better with glucose tolerance than total serum adiponectin in Indo-Asian males. Diabetologia, 48, 10841087. doi:10.1007/s00125-005-1758-7

[22] Pajvani, U.B., Hawkins, M., Combs, T.P., Rajala, M.W., Doebber, T., Berger, J.P., Wagner, J.A., Wu, M., Knopps, A., Xiang, A.H., Utzschneider, K.M., Kahn, S.E., Olefsky, J.M., Buchanan, T.A. and Scherer, P.E. (2004) Complex distribution, not absolute amount of adiponectin, correlates with thiazolidinedione-mediated improvement in insulin sensitivity. The Journal of Biological Chemistry, 279, 12152-12162. doi:10.1074/jbc.M311113200

[23] Wallace, M.B., Mikks, B.D. and Browning, C.L. (2001) Effects of cross-training on markers of insulin resintance/ hyperinsulinemia. Medicine \& Science in Sports \& Exercise, 29, 1170-1175. doi:10.1097/00005768-199709000-00008

[24] Menzaghi, C., Trischitta, V. and Doria, A. (2007) Genetic influences of adiponectin on insulin resistance, type 2 diabetes, and cardiovascular disease. Diabetes, 56, 11981209. doi:10.2337/db06-0506

[25] Qi, L., Kang, K., Zhang, C., van Dam, R.M., Kraft, P., Hunter, D., Lee, C.H. and Hu, F.B. (2008) Fat mass-and obesity-associated (FTO) gene variant is associated with obesity: Longitudinal analyses in two cohort studies and functional test. Diabetes, 57, 3145-3151. doi:10.2337/db08-0006 